8 Bennion L, Grundy S. Effects of diabetes mellitus on cholesterol metabolism in man. $N$ Engl f $\mathrm{Med}$ 1977; 296: 1365-9.

9 Caroli A, Gasparoni P, Sardeo G, Volpi A. May insulin treatment in non-insulin dependent diainsulin treatment in non-insulin dependent dia-
betes mellitus (NIDDM) increase the prevalence betes mellitus (NIDDM) increase the prevalence
of cholelithiasis? Proceedings of the International Meeting on Pathochemistry, Pathophysiology and Pathomechanics of the Biliary System. Bologna 1988 March 14-16 (Abstract 150).

\section{Oesophagography and AIDS}

SIR,-In a leading article on gastrointestinal tract involvement by AIDS Gazzard contends that oesophagography has such a poor sensitivity and specificity for diagnosing opportunistic - that is, fungal and viral - oesophagitis that it is an unsatisfactory technique for investigating oesophageal symptoms in HIVpositive patients. ' Recent evidence, however, suggests that double contrast oesophagography is in fact a valuable diagnostic test in these patients. In two separate studies double contrast oesophagography had a sensitivity of approximately $90 \%$ in diagnosing Candida oesophagitis. ${ }^{23}$ The major advantage of this technique over conventional single contrast barium studies is its ability to show mucosal plaques that cannot easily be seen with single contrast techniques. As a result, only mild cases of Candida oesophagitis are likely to be missed on double contrast examinations. Patients with AIDS often have a more fulminant form of candidiasis in which the oesophagus has an easily recognisable 'shaggy' appearance on oesophagography due to multiple plaques, pseudomembranes, and ulcers. ${ }^{4}$ In contrast, herpes oesophagitis is typically seen on double contrast radiographs by discrete, superficial ulcers without evidence of plaques. ${ }^{5}$ Recently, cytomegalovirus (CMV) has also been recognised as a cause of viral oesophagitis in HIV-positive patients. Unlike herpes, CMV may be shown radiographically as large, relatively flat ulcers one or more centimetres in size. ${ }^{46}$ Because herpetic ulcers rarely become this large, the presence of a giant ulcer should be highly suggestive of CMV oesophagitis in patients with AIDS.

A recent study of HIV-positive patients confirmed that these various types of opportunistic oesophagitis can usually be differentiated by their characteristic features on double contrast oesophagrams, eliminating the need for endoscopic intervention in many cases. ${ }^{+} \mathrm{We}$ therefore believe that double contrast oesophagography is a valuable technique for investigating AIDS patients with oesophageal symptoms. Nevertheless, endoscopy may be required for a more definitive diagnosis if the radiographic findings are equivocal or if the patient fails to respond to appropriate treatment with antifungal or antiviral agents.

MARC S LEVINE HANS HERLINGER
Department of Radiology, Hospital of the University of Pennsylvania 3400 Spruce Street Philadelphia PA 19104

1 Gazzard BG. Practical advice for the gastroenterologist dealing with symptomatic HIV disease. Gut 1990; 31: 733-5.

2 Levine MS, Macones AJ, Laufer I. Candida esophagitis: accuracy of radiographic diagnosis. esophagitis: accuracy of radiog
Radiology 1985; 154: 581-7.

3 Vahey TM, Maglinte DDT, Chernish SM. Stateof-the-art barium examination in opportunistic of-the-art barium examination in opport
esophagitis. Dig Dis Sci 1986; 31: 1192-5.

4 Levine MS, Woldenberg R, Herlinger H, Laufer I. Opportunistic esophagitis in AIDS: radiographic Opportunistic esophagitis in AIDS: radiog
diagnosis. Radiology 1987; 165: 815-20.

5 Levine MS, Loevner LA, Saul SH, Rubesin SE, Herlinger H, Laufer I. Herpes esophagitis: sensitivity of double contrast esophagography. $A \mathcal{F R}$ 1988; 151: 57-62.
6 Balthazar EJ, Megibow AJ, Hulnick D, Cho KC, Berenbaum E. Cytomegalovirus esophagitis in AIDS: radiographic features in 16 patients. $A \mathcal{F R}$ 1987; 149: 919-23.

\section{Reply}

SIR,-Thank you for giving me the opportunity to reply to the helpful letter of Levine and Herlinger discussing the merits of radiology $v$ endoscopy in HIV antibody positive patients. Double contrast barium swallow in expert hands undoubtedly produces fine mucosal detail of the oesophagus, but at the expense of some false positives ( 5 out of 34 ) in the study quoted by Levine and Herlinger.

Any assessment of sensitivity only applies to a particular population. Thus in one of the references that they have cited ${ }^{\prime}$ only patients with oesophageal candidiasis were studied and in the other ${ }^{2}$ only two of 18 cases had an alternative opportunistic infection (herpes). Had a wider spectrum of patients been chosen the sensitivity for radiology might well have been considerably reduced.

The preference for endoscopy in the diagnosis of HIV-related oesophageal symptoms is pragmatic. The sensitivity is likely to be higher than that for radiology in most hospitals and the capacity to biopsy dubious lesions is a major advantage. The major theoretical disadvantage is the transmission of HIV to staff or other patients - this has not been described.

B G GAZZARD

Westminster Hospital,

Levine MS, Macones AJ, Laufer I. Candida esophagitis: accuracy of radiographic diagnosis.

2 Vahey TM, Maglinte DDT, Chernish SM. Stateof-the-art barium examination in opportunistic esophagitis. Dig Dis Sci 1986; 31: 1192-5.

\section{BOOK REVIEWS}

Hepatology for the clinician. A problemorientated approach. By S Beker. (Pp 369; illustrated; \$96.) New York: Alan R Liss, 1989.

Hepatology for the Clinician, edited by $\mathrm{Dr}$ Beker, uses the problem oriented approach and is designed to be read by clinicians caring for patients with liver disease. Its 13 chapters come from authors in the United States, Venezuela, and Japan.

The first thing to be said about this book is that it was a pleasure to read. Its size and the length of the chapters mean that a topic can be read in a short space of time. Most chapters give an insight into how the individual authors tackle a clinical problem rather than give an exhaustive review of the literature on the subject.

Most of the common problems in hepatology are covered with chapters devoted to jaundice, gastrointestinal haemorrhage, ascites, hepatic encephalopathy, acute hepatitis, and chronic liver disease. There are excellent chapters on pregnancy and the liver and on spaceoccupying lesions of the liver. In a book of this kind some chapters inevitably tend to become a little imbalanced. This is particularly evident in the chapter on ascites where the subject of spontaneous bacterial peritonitis is allocated twice as much space as the discussion of ascites and the hepatorenal syndrome combined. The chapter on the febrile patient and the liver is disappointing as it consists mainly of a listing of infectious disorders involving the liver with descriptions of each. A more problem oriented approach here with perhaps discussion of the management of the patient with established liver disease presenting with pyrexia would, in my view, enhance this book.

Despite these criticisms this is an enjoyable book to read. It gives straightforwrd advice about the approach to and management of problems in patients with liver disease. I think it succeeds in its aim of providing practical guidelines for patient management. It is not a substitute for, nor is it intended to be a substitute for, the more comprehensive textbooks in hepatology. I think that it will be read with enjoyment by gastroenterologists, internists, and fellows in training.

P A McCORMICK

Radiology of the small intestine. By P Bret, C Cuche, and G Schmutz. (Pp 400; 550 figs; DM398.) Paris: Springer-Verlag, 1989.

This is a welcome translation of one of France's leading gastrointestinal radiologist's work on the small bowel. One of the first impressions of this book is of the outstanding quality of the radiographs. As Igor Laufer mentions in his preface, it is a beautiful work and a pleasure to look through. The book also has a very practical emphasis. Each section finishes with a short paragraph on 'practical conclusions' and the text is full of helpful points on technique, interpretation, and differential diagnosis that reflect the immense experience of the authors. Ultrasound, computed tomography, and arteriography are discussed, though most of the book concentrates on barium studies. It was refreshing not to find a total insistence on the small bowel enema as the only method for examination. I agree with its recommendation for use in obstruction and was particularly pleased to see the insistence on routine compression during examination with 'each loop separated from the neighbouring one by the Holzknecht device.' This is a useful compression device unfortunately not in common use in the United Kingdom. The index is slightly limited with one page references only to main topics, but, as this is not a reference tome but a book to read through and learn the practical aspects of small bowel radiology, I do not consider this a real disadvantage. I liked this book. There is competition in the field, but this is a particularly good account of the everyday problems encountered when examining the small bowel.

C I BARTRAM

The development of American gastroenterology. By J B Kirsner. (Pp 480; illustrated; \$71.) New York: Raven Press, 1990.

Digestive Disease Week is the annual magnet that lures increasing numbers of gastroenterologists from all over the world to the United States; it is now the undisputed 'unofficial world congress.' The reason for this is meticulously displayed in this considerable work of scholarship; the Americans' contribution to gastroenterology is a rich scientific and clinical heritage which lends a lustre to their meetings. Joe Kirsner is, at 81 , some 12 years 